\title{
Crenças de autoeficácia de professores: um fator motivacional crítico na educação inclusiva
}

José Aloyseo Bzuneck*

\section{Resumo}

Além de habilidades de ensino, professores devem ter crenças de autoeficácia bem desenvolvidas, que consistem nas crenças de que podem atuar com êxito até em classes com clientela diversificada. Pesquisas têm comprovado a proposta de Bandura de que professores com tais crenças mais robustas consideram que todos os alunos podem aprender e, assim, são mais comprometidos e motivados para criar condiçôes propícias ao desenvolvimento de cada aluno em classe. São mais persistentes e mais resilientes após fracassos. Dados de pesquisa também têm produzido apoio à proposta de Bandura de que professores numa escola acabam por desenvolver um senso de eficácia coletiva que, quanto mais robusto, influencia cada indivíduo a ter mais persistência nas dificuldades e a ter expectativas mais elevadas quanto a seus alunos. No presente artigo, são apresentadas as condições por meio das quais são incrementadas, na Educação Inclusiva, tanto a autoeficácia como a eficácia coletiva, assim como suas consequências para os alunos.

Palavras-chave: Professores da educação inclusiva; Crenças de autoeficácia; Eficácia coletiva.

* Professor doutor da Universidade Estadual de Londrina, Londrina, Paraná, Brasil. 


\section{Teachers' self-efficacy beliefs: a critical motivational factor in inclusive education}

\section{Abstract}

Teachers are supposed to master teaching skills, but they have also to hold well established self-efficacy beliefs. That is, they must belief that they can accomplish successfully specific tasks even in classes with students' large diversity. Researchers have documented Bandura's proposal that teachers with strong self-efficacy beliefs think that all their students can learn and therefore they are more compromised and motivated for create conditions necessary for the development of every student in their classes. They are more persistent and more resilient after failures. Research findings have also supported Bandura's claim that in school teachers must achieve a strong collective efficacy that influences every individual to be persistence after setbacks and to have higher expectancies for their pupils. In this paper conditions are showed to further individual and collective efficacy beliefs in Inclusive Education, so that benefits for all students be assured.

Keywords: Teachers in inclusive education; Self-efficacy beliefs; Collective efficacy.

\section{Introdução}

Em qualquer sala de aula, engajamento e comprometimento constituem duas características básicas que se esperam de todo professor ou professora, para que seja eficaz sua atuação junto aos alunos. Engajamento foi definido por Schaufeli, Bakker e Salanova (2006) como "um estado de espírito positivo, que proporciona satisfação no trabalho, e que é caracterizado por vigor, dedicação e absorção" (p. 702). O vigor, segundo esses autores, é caracterizado por altos níveis de energia e de resiliência mental no trabalho, associados à disposição de investir esforço no próprio trabalho, com persistência, mesmo diante de dificuldades. Dedicação significa estar intensamente envolvido no próprio trabalho e experimentar um senso de relevância, entusiasmo, inspiração, orgulho e desafio. Finalmente, absorção é caracterizada por concentraçáo plena no próprio trabalho, pelo que o tempo passa rápido e a pessoa tem dificuldade de se desligar dele.

Paralelamente a engajamento, alguns autores, como Fives e Alexander (2004), trabalharam com o conceito de comprometimento. Professor comprometido é aquele que apresenta ligaçóes psicológicas com o ensino e se sente decididamente identificado com sua profissáo. Assim, o docente realmente comprometido é aquele que sente afinidade com seu trabalho como educador e, mais especificamente, sincera preocupação pelos alunos que atende.

Entretanto, engajamento e comprometimento, particularmente indispensáveis na educação inclusiva, acontecerão sempre em situaçôes concretas de desafios. Está bem documentada na literatura (por ex., SKAALVIK; SKAALVIK, 2010; TSCHANNEN-MORAN; WOOLFOLK HOY, 2007) que os professores e professo- 
ras têm condição de identificar plenamente os diversos desafios, internos e externos, ligados à sua profissão. Para citar os mais óbvios e importantes, apenas do contexto imediato da escola, quem ensina se defronta com classes que apresentam grande diversidade de alunos, em termos de motivação, capacidade, conhecimentos de base, comportamentos, nível socioeconômico, apoio familiar e influências de colegas, positivas e negativas. Adicionalmente, o clima psicológico da escola, que engloba particularmente tipos de relacionamento com colegas, com os gestores e com os alunos, constitui fator potencialmente vital para a eficácia do ensino de cada professor. Consequentemente, esse conjunto de desafios supôe nos professores uma motivação da mais alta qualidade e que é sempre contextualizada. Motivação consiste num processo interno que leva a pessoa à ação e a sustenta, sempre em direção a metas (SCHUNK; MEECE; PINTRICH, 2014).

Deve-se ter em mente, porém, que motivação não é uma entidade simples, unitária, passível de ser avaliada apenas em termos de sua presença em certo grau ou de sua ausência. Ela é considerada multifatorial, isto é, ela se compóe de muitos fatores ou constructos específicos. A motivação pode também variar em termos qualitativos. Segundo Holzberger, Philipp e Kunter (2013), os constructos motivacionais que tradicionalmente têm sido usados para descrever a motivação de alunos também têm sido utilizados para explicar diferenças nos comportamentos dos professores. Assim, nos estudos empíricos recentes com professores têm sido considerados diversos constructos motivacionais, como autoeficácia, motivação autônoma ou controlada, orientaçóes a metas de realizaçáo, expectativa e valor, interesse e entusiasmo. A característica comum a todos esses estudos é que, em função de tais constructos, a motivaçáo apareceu relacionada, de alguma forma, com ensino de boa qualidade e aprendizagem dos alunos.

Para o presente artigo, selecionou-se examinar, como constructo motivacional de professores e professoras, suas crenças de autoeficácia, especificamente relacionadas à condição de atenderem a classes inclusivas. Autoeficácia percebida pertence à grande categoria de autopercepçóes de capacidade ou competência, mas que tem um significado mais restrito e bem preciso. Bandura, que nos anos 1970 introduziu esse conceito na literatura psicológica, com sua teoria social cognitiva, definiu-o como "crenças das pessoas em suas capacidades para organizar e executar cursos de ação necessários para alcançar certos tipos de desempenho" (BANDURA, 1997, p. 3). No caso de professores, a definiçáo tem sido ainda mais diferenciada. Por exemplo, Tschannen-Moran, Woolfolk Hoy e Hoy (1998), autores tradicionalmente envolvidos em pesquisas sobre o constructo, as crenças de autoeficácia de professores se referem às próprias capacidades de exercer açóes em sala de aula, com o objetivo de afetar a autoeficácia, a motivação e o desempenho dos alunos. Com tais especificaçóes, tenhase presente que tais crenças consistem de autojulgamentos ou expectativas, porém náo equivalem a autoconceito, o qual se refere a categorias mais amplas de objetos (BONG; SKAALVIK, 2003; BZUNECK, 2009).

Adicionalmente, a partir de proposta do próprio Bandura (1997), diversos autores têm trabalhado com o conceito de eficácia coletiva de professores (BZUNECK; 
GUIMARÁES, 2009), igualmente de alta relevância, uma vez que os professores de uma escola atuam em boa medida como grupo. Trata-se, segundo definiçáo de Goddard, Hoy e Woolfolk Hoy (2004), de "julgamentos dos professores de uma escola de que o conjunto de que faz parte é capaz de organizar e executar os cursos de ação exigidos para se conseguirem resultados positivos junto aos alunos" (p. 4).

\section{Evidências da relevância das crenças de eficácia de professores}

Bandura (1986; 1997) destacou que a crença nas próprias capacidades para atingir resultados desejados, é poderoso fator de influência sobre a motivação para agir, para o estabelecimento de metas, a aplicação de esforço e persistência diante de dificuldades e até de fracassos. Assim, no caso específico de professores, a literatura das últimas décadas tem documentado esses efeitos de modo consistente, o que consta de revisões como as de Carlotto et al. (2015), Fernandez et al. (2016), Holzberger et al. (2013) e Kleinsasser (2014), para citar algumas das mais recentes.

Como amostra de resultados relatados obtidos pelos inúmeros autores constantes dessas revisôes, autoeficácia de professores apareceu associada aos seguintes efeitos: estabelecimento de objetivos elevados para seus alunos; comportamentos de organizaçáo, planejamento e promoção de atividades baseadas na aprendizagem do aluno; senso de compromisso e a satisfação do professor na escola; baixos níveis de burnout; bom manejo de classe; disposiçáo para adotar práticas inovadoras, inclusive de base tecnológica; promoção de autonomia dos alunos; enfrentamento de situaçóes desafiadoras na escola; motivação e bons desempenhos acadêmicos dos alunos. Resultados similares foram encontrados nas pesquisas sobre eficácia coletiva de professores (BZUNECK; GUIMARÃES, 2009). Dessa relação, conclui-se que crenças robustas de autoeficácia constituem condição indispensável, embora não única, para que os professores sejam mais engajados e comprometidos com sua atividade em classe.

Vale observar que esses correlatos, bem como a própria existência dos constructos autoeficácia e eficácia coletiva, foram encontrados em diversas culturas. Vieluf; Kunter e Van de Vijver (2013), em sua revisão de estudos que abrangeram um total de 73.100 professores de 24 países, Brasil incluído, descobriram que para todos têm igual significado os itens representativos de autoeficácia constantes das escalas aplicadas. Assim, esse resultado dá apoio à proposta de Bandura do caráter transcultural desse constructo.

\section{Crenças de eficácia e a educação inclusiva}

Com base numa observação comumente partilhada, toda classe escolar é heterogênea, em certo grau, por contar com alunos que trazem diferenças de capacidades, conhecimentos prévios (de competência linguistica, por exemplo), de motivação, facilidade ou dificuldades de aprendizagem, entre outros fatores, com a agravante de alguns apresentarem problemas comportamentais associados, como indisciplina em classe. Com a inclusão, as classes apresentarão uma heterogeneidade mais estendida, ao incluírem os portadores de diversos tipos de deficiência, como a intelectual, a fí- 
sica, auditiva, a múltipla etc., em graus diversos. Para a educação, esse fato novo traz consequências para a motivação do professor e, em particular, para a sua autoeficácia.

Tschannen-Moran, Woolfolk Hoy e Hoy (1998; ver também WOOLFOLK HOY \& DAVIS, 2006), baseados em Bandura (1997), esclareceram que os julgamentos de eficácia dos professores resultarão da ponderação combinada de dois processos mentais. O primeiro consiste numa avaliação pessoal do peso relativo de fatores que tornam fácil ou difícil o cumprimento de determinada tarefa de ensino. Essa avaliação, por sua vez, é feita pela análise da tarefa em questão, num contexto bem definido, que inclui até o clima psicológico da escola e a liderança dos gestores. O segundo processo é uma autoavaliação das próprias capacidades e limitaçôes relativamente à execução da tarefa, ou seja, os julgamentos das próprias capacidades têm como base o autoconhecimento de seus pontos fortes e pontos fracos. Portanto, não terá valor preditivo de açóes práticas um julgamento de autoeficácia independente do contexto percebido ou que não contemple açóes definidas como resposta. Instrumentos de medida desse constructo que não considerem explicitamente as condiçôes de ensino, além da autopercepção de capacidade para enfrentá-las, não estarão medindo a autoeficácia tal como fora preconizada por Bandura (1997).

Na mesma linha, Summers, Davis e Woolfolk Hoy (2017) sugeriram que, em toda pesquisa sobre autoeficácia de professores, é necessário investigar explicitamente suas percepçôes da dificuldade da tarefa, uma exigência também defendida por Bong (2005). A escala de Tschannen-Moran \& Woolfolk Hoy (2001), muito prestigiada entre os pesquisadores, contém itens de autoeficácia relativos a três categorias de ação docente: estratégias de ensino, de manejo de classe e para motivar os alunos. Um bom exemplo de item, nesse questionário, representativo de autoeficácia para manejo de classe vem com esta redação: "Em que medida você se julga capaz de controlar comportamentos perturbadores em sua aula?” . Redação muito similar consta da escala construida por Sharma, Loreman e Forlin (2012), específica para a educação inclusiva. Nesse item está explicitada a avaliação da própria capacidade de agir e de exercer controle nas aulas e, por outro lado, que será frente a comportamentos indesejáveis de certos alunos.

Em relação às condições específicas de classes inclusivas, em nosso meio, Duek (2014) descreveu com propriedade os desafios e limitaçóes que acometem todo professor ou professora, apontando que eles sentem dúvidas e desconfiança em relação à sua capacidade de ação. Dúvidas e desconfiança quanto a si próprios são reveladores claros de crenças de autoeficácia abaladas, segundo Bandura (1997). Da mesma forma, na revisão de estudos nacionais sobre as concepçóes de professores em relação à educação inclusiva (SILVEIRA, ENUMO; ROSA, 2012), apareceram indicadores de que professores e professoras avaliam as condiçôes da execução desse projeto como superiores à sua capacidade de ação. Em particular, foram colocados como problemas o autoisolamento de alunos com certas deficiências e a incapacidade de aprendizagem, fato mais grave nos casos de deficiência múltipla. Descobriu-se também que, em função de baixas expectativas quanto ao atendimento adequado dessa categoria de alunos, professores tendiam e exclui-los do grupo. Essa é uma 
consequência perversa do baixo nível de autoeficácia, que merece ser apreciada mais detalhadamente.

Em sua própria pesquisa recente, Summers; Davis e Wookfolk Hoy (2017) descobriram que as crenças de eficácia de professores afetavam a variância da percepção por parte de seus alunos de que havia relacionamento de boa qualidade com seus professores ou professoras. Isto é, os alunos declaram que se sentiam mais bem relacionados com seus professores ou professoras quando eles apresentavam crenças mais robustas de autoeficácia. Os autores explicaram a importância de bons relacionamentos entre professores e alunos à luz da teoria do apego, o que faz sentido, tendo em vista as consequências positivas previsíveis. Entretanto, há uma teoria motivacional amplamente adotada em pesquisas, a Teoria da Autodeterminação (RYAN; DECI, 2004), que fornece uma explicação mais a fundo para se compreender a relevância da autoeficácia para os relacionamentos interpessoais na escola.

De acordo com Ryan e Deci (2004), alunos desenvolverão uma motivação de qualidade superior, chamada motivação autônoma (motivação intrínseca é o subtipo mais avançado), com a condição de perceberem que seus professores atendem a três necessidades psicológicas básicas: autonomia, competência e relacionamento. Assim, na hipótese de algum aluno não ter atendido alguma dessas três necessidades psicológicas, como a de relacionamento, que equivale à experiência de pertencer ao grupo e de se sentir afetivamente vinculado a outros, sua própria motivação perderá qualidade ou sofrerá abalo, caindo num estado de desengajamento e apatia (GUIMARÃES, 2010). Sentir-se relacionado, vinculado e pertencente àquele grupo é uma das condiçôes necessárias para o aluno manter uma motivação da mais alta qualidade. Por essa razão, prevê-se que, quando forem reduzidas as crenças de autoeficácia de professores da educação inclusiva, o efeito final será a desmotivação e desengajamento de muitos de seus alunos. O que medeia essa relação são comportamentos dos professores de não atenderem à necessidade psicológica de relacionamento dos alunos, ou seja, deixam de acolhê-los e atendê-los devidamente e até os marginalizam.

Para casos como esse, é razoável admitir a mesma avaliação já identificada em escolas com outro tipo de alunos. Ao referir-se a dados de pesquisa que revelavam baixas crenças de eficácia de professores que atendiam classes com alunos de nível socioeconômico inferior e que eram mal atendidos, Takahashi (2011), da Universidade de Harvard, observou que é justamente com tais alunos que os professores precisam ser mais criativos, empenhados e persistentes. Ora, concluiu a autora, parece que as escolas que mais precisam de inovação e compromisso coincidem com as escolas cujos educadores estão menos motivados para buscar soluçóes. Essa observação, que calha muito bem em relação ao contexto brasileiro, fornece um referencial para se entender porque, em classes inclusivas (não somente nelas), tem sido identificado o problema de se deixar de lado alunos que apresentem alguma diferença importante, ou algum tipo de necessidade especial, logo aqueles que mais precisam de atençáo, acompanhamento e ajuda. 


\section{Desenvolvimento da autoeficácia de professores}

Se o estabelecimento de crenças de autoeficácia é tão crucial na educação inclusiva e se, por outro lado, professores e professoras têm revelado abalo desse fator motivacional, surge a questão: qual é a origem dessa crenças, isto é, que fatores respondem pelo seu desenvolvimento e manutenção? Bandura (1997) propôs que, nas pessoas, autoeficácia emerge de quatro possíveis fontes: experiência de êxito, persuasão verbal, experiências vicárias e ativação psicofisiológica. Tschannen-Moran e Woolfolk Hoy ( 2007), entre outros autores, examinaram essas fontes no caso de professores

Em primeiro lugar, as crenças de eficácia serão alimentadas se um professor perceber que com sua atuação em classe tem atingido bons resultados, que consistem em que seus alunos estão aprendendo, fazem progresso, desenvolvem-se intelectualmente, ou apresentam comportamentos mais adequados nas aulas. Resultados como esses atestam para o próprio professor ou professora que tem capacidades e assim contribuirão para a expectativa de que, no futuro, provavelmente também será bem sucedido. Já as crenças de eficácia se enfraquecerão caso ele experimente fracassos, já que produzirão uma expectativa de que, muito provavelmente, não terá capacidade, no futuro, de enfrentar desafios semelhantes com êxito.

A segunda fonte de autoeficácia consiste em verbalizaçóes de persuasão verbal, advindas de colegas, gestores ou de outras pessoas, que contenham a informação de que o professor está indo bem no ensino ou que pode alimentar as melhores expectativas de sucesso.

As experiências vicárias consistem em o professor enxergar que colegas, com mesmo nível de formação e capacidade, estão sendo bem sucedidos e, portanto, atuam como modelos de referência para o próprio julgamento. O impacto do modelo, porém, sobre as crenças de eficácia do observador dependerá do grau em que o observador se identificar com o modelo.

Por último, a ativação psicofisiológica e emocional também contribui para um sentimento de capacidade ou de incompetência. Assim, sentimentos de satisfação ou prazer que um professor experimentar em sua classe favorecerão seu senso de eficácia. Pelo contrário, altos níveis de estresse ou de ansiedade, associados ao medo de perder o controle, podem resultar em enfraquecimento da crença de autoeficácia. Na revisão de pesquisas com professores da educação inclusiva, Silveira, Enumo e Rosa (2012) relataram que, ao menos num estudo, professores expressaram sentir medo e angústia, emoções que justamente sinalizam autopercepção de baixa capacidade para dar conta dos desafios nessa área.

Dessas quatro fontes propostas por Bandura (1997) a persuasão verbal e a experiência vicária têm conotação interpessoal, pois ambas dependem de outras pessoas. Verbalizaçôes de persuasão verbal representam formas de feedback positivo que tem, normalmente, alto impacto sobre a motivação de quem as recebe. Questiona-se se faz parte do clima das nossas escolas a prática de professores ouvirem tais palavras de apoio. Entretanto, mesmo que um professor ou professora tenha colegas como 
modelos de desempenho bem sucedido naquele contexto, ou que lhe transmitam verbalmente a informação de que tem capacidades ou que está tendo bons resultados, em ambos os casos essa influência social tem limites. Primeiro, porque todo professor faz uma interpretação do que enxerga nos modelos e do que ouve dizer de positivo a seu respeito (WOOLFOLK HOY; DAVIS, 2006). Assim, por exemplo, ao perceber que uma colega de escola está sendo bem sucedida, uma professora pode interpretar que sua colega tem melhores condiçóes, sejam elas pessoais ou ambientais, e assim desconsidera sua pessoa como modelo. $\mathrm{O}$ mesmo vale quando alguém lhe passar a informação de que é bem dotada de habilidades de ensino. Diversas interpretaçóes podem passar por sua cabeça, inclusive que dizem isso por pura bondade ou para consolo.

Ao lado dessas possibilidades de interpretação das influências de origem social, há uma limitação de fundo, inerente a essas duas fontes. Nenhuma delas contribuirá para a autoeficácia caso não se verifique a primeira fonte, que são experiências anteriores de êxito real. Neste sentido, Bandura (1997) foi incisivo. Para esse autor tais experiências "representam a fonte mais influente de informação sobre a eficácia porque elas proporcionam a evidência mais autêntica de que a pessoa pode dar conta do que é preciso para ter êxito" (p.80). Supôe-se que, na educação inclusiva, todo professor ou professora comece por dar o melhor de si, desde o início do exercício do ensino. Caso essa aplicação de esforço e dedicação sejam por eles percebidos como eficazes, esse resultado atestará claramente que tem as capacidades exigidas, ou seja, aí é alimentada sua autoeficácia. Ao contrário, fracassos ou resultados minguados, apesar de empenho e compromisso, levam inevitavelmente à convicção de que o que lhe falta é capacidade e, portanto, a autoeficácia entra em queda livre. Em suma, para a construção da autoeficácia de um professor ou professora, de nada adiantaria ouvir frases de conteúdo elogioso, se os fatos revelarem que os seus esforços têm sido em vão, já que algo crucial está faltando. Mesmo com as tentativas amimadoras de persuasão verbal, não há como acreditar na capacidade de chegar a bons resultados.

Nesse contexto, surge a necessidade, em particular na educação inclusiva, de algo mais do que ter crenças de autoeficácia. Que todo professor ou professora tenha tais crenças bem estabelecidas é condição necessária para a motivação e para bons resultados no ensino, como atestam os resultados de pesquisas inspiradas na teoria social cognitiva de Bandura (1997), mas tais crenças não são suficientes. Schunk (1991) e Wheatley (2005) ponderaram que, para bom desempenho, tais crenças não suprem falhas de conhecimentos e habilidades reais, exigidas no ensino, porque são elas que, basicamente, tornam possíveis as açóes eficazes. Embora Bandura (1986) tenha admitido que possa ser benéfica uma crença de eficácia de nível pouco acima da real capacidade, uma disparidade acentuada logo acarretará fracasso e, portanto, será contraproducente para a autoeficácia.

Em suma, para a motivação, é necessário que os professores acreditem que são capazes de colocar açóes eficazes no ensino, mesmo com certa benevolência nessa avaliaçáo. Mas é igualmente imprescindível que disponham de conhecimentos e habilidades reais para enfrentarem com êxito os desafios de sua profissão. Wheatley 
(2005) declarou não conhecer nenhum estudo experimental em que se tenha conseguido produzir mudanças na autoeficácia de professores, quando eram controlados os conhecimentos e sua real eficácia no ensino. Só tem sentido motivacional e relevância educacional a promoção de mudanças nas crenças de autoeficácia quando acompanhada de melhoria de conhecimentos de base indispensáveis.

Em nosso meio, professores e professoras têm admitido explicitamente sentirem falta, entre outras condições, de melhor capacitação para atuarem em classes inclusivas, como consta de diversos estudos (por ex. CRUZ; GLAT, 2014; DUEK, 2014; LIMA e DIAS; ROSA; ANDRADE, 2015; SILVEIRA; ENUMO; ROSA, 2012). Conhecimentos e habilidades desenvolvidas nos cursos de formação e na capacitação continuada têm o potencial, ao lado de outras condiçóes, de garantir bons resultados no ensino, quando também estiverem presentes as crenças de autoeficácia. Mas os bons resultados experimentados continuam sendo a fonte mais importante da própria autoeficácia e, portanto, da motivação para continuar com engajamento e compromisso.

\section{Considerações finais}

O foco do presente artigo, foram as crenças de autoeficácia de professores como condiçãoo indispensável para atuarem com êxito na educação inclusiva. Foram descritas as consequências positivas desse sistema de crenças, bem como foi sugerido o que é preciso ser feito, e por quais razóes, para o seu desenvolvimento e manutençáo. Entretanto, à guisa de fechamento, algumas consideraçóes parecem oportunas.

Tschannen-Moran e Woolfolk Hoy (2007) observaram que, assim que iniciam seu trabalho numa escola, logo após a graduaçáo, muitos professores tendem a revelar elevada autoconfiança quanto ao impacto que exercerão sobre seus alunos, ou seja, por alguma razão começam com uma autoeficácia bem estabelecida. Não é raro, porém, que logo se defrontem com um doloroso "choque da realidade", quando se dâo conta de que pode ser mais difícil do que pensavam conseguir os resultados que esperavam de seus alunos. Esse fato pode levar os novatos, em função de dúvidas sobre suas capacidades de ensino, a rebaixarem o nível de seus objetivos educacionais e, inconscientemente, a reduzirem seu engajamento, ao menos em relação a certos alunos. Trata-se, segundo esses autores, de uma forma de autoproteção, com o objetivo de evitar a dolorosa constataçáo de fracasso pessoal.

Por outro lado, segundo Wheatley (2005), o surgimento de alguma dúvida sobre a própria eficácia, nesta altura, pode ser benéfico. Quem se fecha numa autopercepção de eficácia cristalizada, atruibuindo os fracassos a outras pessoas ou a condiçôes adversas fora de sua influência, não fará nada para rever o próprio ensino e as próprias crenças. Já professores realmente comprometidos com a educação pensam em desenvolvimento profissional, que exigirá uma disposição para, com autorreflexão, identificar em si próprio tanto pontos fortes como eventuais deficiências e buscar caminhos de superá-las. Na prática, algumas aprendizagens novas devem acontecer.

É conveniente ter como princípio de que, com certos alunos, não se podem esperar resultados imediatos, como acontece com outros. Não se pode determinar que, 
em classe, com a mediação do professor, todos devem chegar juntos aos mesmos resultados. Bandura (1986) já havia advertido para os efeitos perversos de uma prática pedagógica do tipo marca forçada, em que a classe como um todo, mesmo heterogênea, tenha que avançar de modo homogêneo. O desafio, portanto, é aprender a lidar com os diferentes alunos, calibrando tanto os objetivos como o ritmo de exigências escolares, o que supóe, por parte dos professores da educação inclusiva, novas aprendizagens e treinamento de habilidades relativas a certa individualização no ensino.

\section{Referências}

BANDURA, A. Social foundations of thought and action: a social cognitive theory. Eng-lewood Cliffs, NJ: Prentice-Hall, 1986.

Self-efficacy: the exercise of control. New York:W.H. Freeman and Company, 1997.

BONG, M. Asking the right question: How confident you are that you could successfully per-form these tasks? In: PAJARES, F.; URDAN, T. (Ed.) Self-efficacy of adolescents. Greenwich, Conn.: Information Age Publ., 2005. p. 287-305.

BONG, M.; SKAALVIK, E. M. Academic self concept and self-efficacy: how different are they really? Educational Psychology Review, v. 15, n. 1, p. 1-40, 2003.

BZUNECK, J. A.; GUIMARĀES, S. E. R. Eficácia coletiva dos professores e implicaçôes para o contexto brasileiro. Educaçáo Temática Digital, Campinas, v. 10, p. 1-15, 2009. Número especial.

BZUNECK, J. A. A Motivação do aluno: aspectos introdutórios. In: BORUCHOVITCH; E.; J. A. BZUNECK, J. A. (Org.). A Morivaçáo do Aluno. Petrópolis: Vozes, 2009. p. 9-36.

CARLOTTO, M. S. et al. O papel mediador da autoeficácia na relação entre a sobrecarga de trabalho e as dimensōes de Burnout em professores. Psico-USF, Bragança Paulista, v. 20, n. 1, p. 13-23, jan./abr. 2015

CRUZ, G. C.; GLAT, R. Educação inclusiva: desafio, descuido e responsabilidade de cursos de licenciatura. Educar em Revista, Curitiba, n. 52, p. 257-273, abr./jun. 2014.

DUEK, V. P. Formação continuada: Análise dos recursos e estratégias de ensino para a edu-cação inclusiva sob a ótica docente. Educaçáo em Revista, Belo Horizonte, v. 30, n. 2, p. 17-42, abr./jun. 2014.

FERNANDEZ, A. P. O. et al. Overview of research on teacher self-efficacy in social cognitive perspective. Anales de Psicologia, Murcia, v. 32, n. 3, p. 703-802, 2016.

FIVES, H.; ALEXANDER, P. A. How schools shape teacher efficacy and commitment another piece in the achievement puzzle. In: MCINERNEY, D. M.; VAN ETTEN, S. Big theories revisited: Research on sociocultural influences on motivation and learning. Greenwich: Information Age Publishing, 2004. p. 329-359.

GODDARD. D.; HOY, W. K.; WOOLFOLK-HOY, A. Collective efficacy beliefs: theoretical de-velopments, empirical evidence, and future directions. Educational Researcher, Washington, v. 33, n. 3, p. 3-13, 2004.

GUIMARÁES, S. E. R. Necessidade pertencer: um motive humano fundamental. In: BORU-CHOVITCH, E.; BZUNECK, J. A. (Org.). Aprendizagem: processos psicológicos e o contexto social na escola. Petrópolis: Vozes, 2010. p. 177-200.

HOLZBERGER, D.; PHILIPP, A.; KUNTER, M. How teachers' self-efficacy is related to instruc-tional quality: a longitudinal Analysis. Journal of Educational Psychology, Arlington, v. 105, n. 3, p. 774-786, 2013.

KLEINSASSER, R. C. Teacher efficacy in teaching and teacher education. Teaching and Teacher Education, New York, v. 44, p. 168-179, Nov. 2014.

LIMA e DIAS, M. A.; ROSA, S. C.; ANDRADE, P. F. Os professores e a educaçáo inclusiva: identificação dos fatores necessários à sua implementação. Psicologia USP, São Paulo, v. 26, n. 3, p. 453-463, 2015.

RYAN, R. M.; DECI, E. L. An overview of self-determination theory: an organismic-dialectical perspective. In: DECI, E. L.; RYAN, R. M. (Ed.). Handbook of self-determination research. Rochester, NY: The University Rochester Press, 2004. p. 3-33.

SCHAUFELI, W.; BAKKER, A. B.; SALANOVA, M. The measurement of work engagement with a short questionnaire: a cross-national study. Educational and Psychological Measurement, Durham, v. 66, n. 4, p. 701-716, 2006 
SCHUNK, D. H. Self-Efficacy and academic motivation. Educational Psychologist, Hillsdale, v. 26, n. 3, p. 207-231, 1991.

SCHUNK, D. H.; MEECE, J. L.; PINTRICH, P. R. Motivation in education: theory, research, and applications. 4th ed. Boston, Mass., 2014.

SHARMA, U.; LOREMAN, T.; FORLIN, C. Measuring teacher efficacy to implement inclusive practices. Journal of Research in Special Educational Needs, v. 12, n.1, p. 12-21, Jan. 2012.

SILVEIRA, K .A.; ENUMO, S. R. F.; ROSA, E. M. Concepçóes de professores sobre inclusão escolar e interaçōes em ambiente inclusivo: uma revisão da literatura. Revista Brasileira de Educaçáo Especial, Marília, v. 18, n. 4, p. 695-708, out./dez. 2012.

SKAALVIK, E.M.; SKAALVIK, S. Teacher self-efficacy and teacher burnout: a study of rela-tions. Teaching and Teacher Education, New York, v. 26, n. 4, p. 1059-1069, 2010.

SUMMERS, J. J.; DAVIS, H. A.; WOOKFOLK HOY, A. The effects of teachers' efficacy beliefs on students' perceptions of teacher relationship quality. Learning and Individual Differences, v. 53, p. 17-25, Jan. 2017.

TAKAHASHI, S. Co-constructing efficacy: A "communities of practice" perspective on teach-ers' efficacy beliefs. Teaching and Teacher Education, New York, v. 27, n. 4, p. 732-741, May 2011.

TSCHANNEN-MORAN, M.; WOOLFOLK HOY, A. Teacher efficacy: Capturing an elusive con-struct. Teaching and Teacher Education, New York, v. 17, n. 7, p. 783-805, Oct. 2001.

TSCHANNEN-MORAN, M.; WOOLFOLK HOY, A. The differential antecedents of self-efficacy beliefs of novice and experienced teachers. Teaching and Teacher Education, New York, v. 23, n. 6, p. 944-956, Aug. 2007.

TSCHANNEN-MORAN, M.; WOOLFOLK HOY, A.; HOY,W. K. Teacher efficacy: its meaning and measure. Review of Educational Research, Washington, v. 68, n. 2, p. 202-248, summer 1998.

VIELUF, S.; KUNTER, M.; VAN DE VIJVE, F. J. . Teacher self-efficacy in cross-national per-spective. Teaching and Teacher Education, New York, v. 35, p. 92-103, Oct. 2013.

WHEATLEY, K. F. The case for reconceptualizing teacher efficacy research. Teaching and Teacher Education, New York, v. 21, n. 7, p. 747-766, Oct. 2005.

WOOLFOLK HOY, A.; DAVIS, H. A. Teacher self-efficacy and its influence on the achievement of adolescents. In: PAJARES, F.; URDAN, T. (Ed.). Self-efficacy of adolescents. Greenwich, Conn.: Information Age Publ., 2006. p. 117-137.

\section{Correspondência}

José Aloyseo Bzuneck - Universidade Estadual de Londrina, Centro de Educação Comunicação e Artes, Departamento de Educação. Jd. Perobal. CEP: 86051-990. Londrina, Paraná, Brasil.

E-mail:bzuneck@sercomtel.com.br

Recebido em 11 de julho de 2017

Aprovado em 11 de agosto de 2017 
